the heart, or obstruction to the current of blood. And this is true in the great majority of cases. But, as we have already seen, there is reason to believe either that this disorganising process may be occasionally of singular slowness, so that the patient may live for many years in the enjoyment of good, or at least tolerable health, or that the diseased action is really arrested and the lesion becomes stationary. I have seen several cases which admit of no other explanation." This is no doubtful utterance, and Dr. Andrew Clark says our present prognosis has become "more favourable." But where certain views are antagonistic to what is generally taught in medical schools, their growth is slow and their progress is impeded at every turn. Students must be taught the gravity of valvular diseases of the heart; about that there can be no diversity of opinion. Whether, when they become practitioners, it does not behove them to instruct themselves as to the other, if rarer, aspect of valve lesions of the heart, or not, is their business, not mine. But I venture to think that patients with injured cardiac valves take such a natural interest in the matter that the members of the profession will have before long to rouse themselves on the subject. Diseases of the nervous system, and the various aspects of the germ theory, have largely absorbed the professional attention of recent years. But the public, who suffer from a variety of maladies, irrespective of whether they are the special subjects of medical study at the time or not, cannot be expected to be so completely carried away by the current of medical thought which happens to be prevalent or uppermost at the time. And this I say as one having some experience, at least in diseases of the heart. I have no wish to disparage the knowledge of the general practitioner, or in any way to undermine the confidence the public repose in him, nor do I forget for one moment the wide range over which his information must necessarily extend. I merely wish to take this opportunity in the well-known Medical Society of London to utter a word of warning as to the necessity for greater intimacy with the diseases of the heart than at present obtains. If I may be permitted to speak from my personal experince, I can say that in the serious, grave, well-marked cases of valvular disease corresponding to what they read as described in their text-books, and which they have seen in the cases shown to them in their student career in the hospital, and in their clinical lectures, they gauge the cases quite correctly and accurately. But when the features are not so well marked, then their want of thorough familiarity with the subject reveals itself, and they regard many cases as graver than they really are. This must be mainly attributed not to want of acumen in the medical men, but rather to the teaching adopted to fit them for their examinations. The detection of a murmur, and the correct appreciation of its preeise locality and maximum intensity, of its time in the cardiac cycle, is what is impressed upon them so earnestly that the importance of regarding the heart as a muscle, governed by the laws which affect muscles generally is largely lost sight of.

Conseqnently the presence of an undoubted murmur at one of the orifices of the heart carries them away at once to the valvular defect of which the murmur is the indication; and not only that, but to the series of morbid sequences which follow that lesion when well established, and passing on to its later and final stages. Now, it is in this inference that their error in the main lies. Amidst the many demands of general practice they cannot read up treatises upon the dis eases of the heart; they have not the time, to say the least of it; and therefore when cases not accurately corresponding to those they are really familiar with present themselves, they are apt to lend to them a gravity not quite justified by the facts, but borrowed from more serious cases. It is against this $I$ wish to warn them.

(To be concluded.)

Mr. E. Lund, surgeon to the Manchester Royal Infirmary, has signified his intention of contributing to the funds of the insticution the sum of $£ 50$ per annum for the next five years.

MR. D. RIChaRds, medical officer to the workhouse and infirmary of the Brighton Union, has been voted the sum of $\mathfrak{E} 50$ for recent extraordinary services rendered on behalf of the town.

\section{ON MEDICAL EDUCATION}

\section{BY H. BRIDGES ADAMS, M.D.}

IN the various contributions to this subject that have appeared during the last few months in THE LANCET, one of the principal and regularly recurring causes of complaint has been the inadequacy of the present system of clinical instruction in hospitals. The complaints that have been made public are a faithful but certainly not exaggerated exponent of the dissatisfaction that cannot fail to be felt by a large body of earnest students and teachers. While this subject is occupying so much attention in medical circles, and proposals of reform are being ventilated on all sides, surely one of the first ideas to suggest itself is, How has this question been attacked, perhaps, even to a certain extent, solved, elsewhere? Taking for granted, as one is certainly justified in doing, that the modes of instruction abroad are well-known to many English clinical teachers, and to a proportionately large number of medical men, who, without being teachers, take a keen interest in the subject, it is not without some surprise that I have observed the omission of any remark on the differences that exist, or of any com. parison between the respective merits of English and foreign methods. Perhaps, under these circumstances, it would not be out of place if I were to give a short description of the way in which clinical teaching is given in the University of Leipzig. The system, which is more or less the same through out Germany, Switzerland, and Austria, differs widely from that pursued in the English and French schools, and a comparison may possibly throw some light on difficult points.

It has already been often and justly remarked, that an hour or an hour and a half divided among thirty to forty patients, and as many students, is utterly inadequate for teaching purposes. However great the competence of the teacher and the application of the learner, it would be a physical impossibility to obtain anything like the desired results in the allotted time, even supposing that all students could see, hear, and examine, which, of course, is far from being the case. Mr. Orchard ${ }^{1}$ suggests that the number of students be limited, and the number of physicians increased. A more systematic plan of instruction, such as that carried out in Leipzig, has, at any rate in that Jniversity, met the difficulty in what I venture to think a more satisfactory way. I proceed to describe the principal features of that plan.

I must preface my remarks by stating that the medical course in Germany is divided into two periods. The first, covering on an average two years, is devoted to the preparatory sciences-anatomy, histology, physiology, organic and inorganic and physiological chemistry, natural philosophy, botany, zoology, and comparative anatomy. As soon as the student feels himself sufficiently strong in these subjects, he goes up for his first, merely oral, examination, the so-called "physicum." Two students are examined together, by five professors in succession. They are at liberty to choose their own day any time during the academic year. The examination lasts one af ernoon; failure in three out of the five subjects, or in physics and chemistry alone, neeessitates re-examination in the others. After the physicum comes the time of medical study proper; the student begins to attend the clinics, and before long to take special courses. The second period covers two or three years, according to the choice, very often accordin $\$$ to the purse, of the student. The two pexiods are bridged over by the last half year of the first, during which the student prepares himself for his clivical studies by a course of pathological anatomy and histology (microscopical), by preparatory courses in medicine and suroery, and by occasional visits to the surgical clinic. With the exception of this preparatory halt year the two periods are kept strictly divided. No one knows better than the student that he caunot run before he can walk; in other words, that patholory must remain a closed book to him till he has acquired a certain amount of introductory knowledge, and this know. ledge the German student finds corresponds pretty well to the course mapped out for him. Till physiology hias taught lim the functions of the heart and of the digestive juices he can understand no case of cardiac or iutestinal disease; till he is well grounded in anatomy he can profit by no surgical operation, can understand no case of new growth; till he 1 The Lancet, July 9th, 1881. 
has mastered at least the elements of botany and zoology the history of parasites will be unappreciated and antiseptics will be a meaningless word.

These preparatory sciences demand a great deal of harl study and undivided attention, and every hour the student spends in a hospital before he has mastered as much of their elements as he requires for his medical study is worse than wasted. Of course, the same reasoning applies to the proposal of apprenticing the student to a medical practitioner for a certain number of years before he begins "to walk the hospitals." Writers to THE LANCET have given expression to this conviction in forcible language, a conviction that many who have the interests of medical education at heart earnestly desire to see gaining ground and taking practical shape.

At the end of the second period comes the great final examination, written, oral and practical, lasting two or three months, with pauses between the various divisions. Here again the student can choose his own time. Four are examined together. The subjects are normal and pathological anatomy and physiology, surgery and ophthalmology, medicine, obstetrics, hygiene, forensic medicine, and materia medica. This reduction in the number of examinations has, in the opinion of many, a salutary effect on the way in which the student works, while it affords the examiner sufficient opportunity for judging of the quality of the work done. Often recurring examinations are a source of much hasty, slovenly work, and it is decidedly the best students from whom one hears the remark: "As soon as the examination is over I can begin to work again with thoroughness and profit." Hither to England and France have given preference to the plan of more frequent examinations. It is worth consideration whether Germany obtains less or more satisfactory results from a different system.

After this introduction I turn to the special description of clinical teaching in Leipzig, and must observe in starting that the manner in which the Leipzig hospital is built facilitates a method which the form of most London hospitals would render more difficult, though by no means impossible. It is built on the one-storeyed pavilion system; almost all the wards and all acute cases are on the same floor as the clinical hall. Ten long pavilions, three of which are medical, each containing twenty to twenty-five beds, and separated by strips of garden, are connected on one (narrow) side by a corridor. In addition to these ten pavilions there are twelve others completely isolated, while the main building has wards on the first and second floors, which are used almost entirely for chronic patients, and those who are not confined to bed. Opposite to this uniting corridor, and opening on to it, is a large amphitheatrical hall capable of holding over two hundred students. The seats are so arranged that each one has a good view of what is going on in the arena below, or being drawn or written on the black board. The beds are all on castors, and the patients whom the professor wishes to demonstrate to the audience are rolled into the hall. The distance is so short that cases such as typhoid and pneumonia can be brought across without danger; the patients them. selves do not object to it. The very ill are indifferent, the moderately ill like the change. Of course, there are cases which cannot be removed, and these are, very occasionally, visited in the wards, but even then the discussion is carried on in the hall. As a means of transport from the upper floors or from isolated pavilions a large covered basket is used, like that employed for fetching the wounded, but the number of acute cases in the three medical wards opposite the hall (more especially in the ward immediately facing it), generally suffices for all purposes of demonstration. The medical division of the hospital is nnder the direction of a professor, who unites the functions of chief physician and clinical teacher, and who has besides a large consulting practice. I mention this fact to show that the amount of time necessarily devoted to this twofold capacity does not interfere with private practice. Under him are four assistant doctors who live in the hospital. Each of them has two or more pavilions under his care, which he is bound to visit night and morning. In addition to this the professor makes the round of the entire medical division of the hospital daily (Sundays included), and thoroughly examines every new or altered case. This visit, on which he is accompanied only by the assistant, has nothing to do with his clinical instruction, but furnishes him with material for it. The clinic occupies an hour and $a$ half daily, and consists in the detailed demonstration of a few cases in the clinical hall. The method of instruction pursued is as follows. All available cases are distributed among the students, so that each student gets on an average ten or more cases in the course of a semester. It is his duty to thoroughly examine those cases and to continue to do so daily, to read up the chapters bearing on them in the handbooks, to study them from every possible point of view. A room is provided in the hospital, with microscopes, for the use of the student, and in each pavilion he finds the apparatus and chemical reagents necessary for examining the urine, sputum, \&c. Neglect to use these opportunities is rarely allowed to pass uncensured. When one of his cases is brought into the hall for demonstration (which is done without his receiving any notice) he has to go into the arena and give a clinical history of the case before professor and students. The professor first listens, then questions and explains, and goes into all the points connected with the disease, its relation to the case in question, cause, course, and treatment. Everybody hears and sees, and, if it is a case of special interest, is invited to examine, always, however, with due regard to the condition of the patient, a principle that is on all occasions strenuously adhered to. Microscopical preparations relating to the cases are prepared beforehand, explained and looked at by all in turn, during or after the clinic. Interesting laryngoscopical or gynæcological cases are demonstrated by the assistants after the clinic, and a limited number of students are allowed to examine, day by day, till all have had their turn. A laryngosecpical course, comprising twelve lessons, is attended by all, and enables the students to examine the larynx for themselves. Six are admitted to the course, which is given by a specialist, and several of which are held in the course of the semester and during the holidays. Acute cases which have been once demonstrated are shown again from time to time, and the changes that have taken place are noticed. The post-mortem examination of every interesting case is made in the presence of the students, the organs are demonstrated and elucidated by microscopical preparations from former cases.

The students are prepared to profit by this really admirable clinical instruction, which no private study of handbooks could replace, by special courses in auscultation and pereussion, in the ordinary methods of examination, such as the different urine tests, \&c., and the elements of clinical symptomatology. One small course, covering four hours weekly during the semester, gives the student a thorough basis of elementary facts, on which he can build up a very fair amount of knowledge in the two or three years during which he continues to visit the clinic. These courses are generally given by the first assistant, and their excellence depends on his capacity. In Leipzig they have long been regarded by the students as one of the most valuable parts of their clinical teaching, and having gone through one is made by the professor a condition of admittance to the more advanced work of the clinic. It would not be ditificult to find able men for the same purpose elsewhere.

To the visit of the English physician to the wards corresponds the nightly visit of the assistants, to which the students bave free access, so that opportunity is thereby given them of following the conrse of any case in which they are interested, of examining at leisure, and of asking questions on any doubtful points. The system is therefore practically a combination of the bedside instruction with the clinical lectures, and unites, it seems to me, the advantages of both. Diseases are discussed at length and in all their bearings, and the discussion is regularly accompanied by the demonstration of cases in point. I should like to draw particular attention to the fact of the bedside instructions being given in a vroperly arranged amphitheatre, where a large number can see and hear, instead of in a ward, whore only a few can see and hear, as this is one of the chief points on which the whole system turns.

A description of the clinical teaching at Leipzig would be very incomplete if it did not include the policlinic, or out patient department. By means of an adequate organisation a large and valuable material is turned to good account, and no Leipzig student can look back on this part of his studies without recognising how much he owes to it.

The medical policlinic is divided into the ambulatorium proper and into the so-called district-policlinic, or patients who are treated at their own houses, and each division is under the direction of a special policlinical professor with two assistants. It is open five days weekly, lasts about an hour and a half, and is visited by patients from far and near. Each student chooses any one or more patients out of those in the waiting-room, and examines them in one of a number of small compartments specially built for this purpose. This 
ensures privacy and a fair amount of quiet. The patients are then in turn demonstrated to the professor and remaining students by the student who has examined. The professor re-examines before the others, cross-questions, explains, and discusses the treatment. The student then prescribes, and his preseription is checked and signed by an assistant before it is given to the patient. Owing to the help of the assistants, the professor is not bound to despatch a given number of patients himself, but can devote as much time as he thinks desirable to any specially instructive case. The plan also forces the students to put all the knowledge they posses into practice, as everyone is desirous of distinguishing himself by correct diagnosis, and anxious to avoid the trifling humiliation of the reverse.

The district-policlinic is attended by more advanced students, as it involves a certain amount of responsibility. Several distriets of the town are placed at the disposal of the University, and the second policlinical professor is at the same time poor-law doctor (Armenarzt). He and his two assistants have daily a consulting hour for the patients of these districts, and visit all acute and bedridden cases in their own homes. A certain number of these patients are distributed among the students, whose duty it then is to visit them, watch their progress, take their temperature, and prescribe. Small operations, such as tapping for ascites, introducing the stomach sound, vaccinating, \&c, are performed by the students under direction. The treatment is controlled by visits from the professor and bis assistants, and twice weekly the students give a detailed report of the cases under their care. The professor takes advantage of the opportunity to criticise and teach, and to comment especially on the practical side of the cases in question. Those students who attend the district policlinic have opportunities of seeing and treating a large number of acute and chronic diseases of children and adults, especially epidemics of the former. The great value of these visits is that they bring the student in contact with patients in their own homes, that they give him an insight into the difficulties that beset private practice, and make him practically familiar with the ordinary everyday disease with which he will most frequently have to deal.

The surgical and obstetric clinics and policlinics are arravged on the same principles, subject to such modification in detail as the condition of the patients renders necessary. In both departments the students are allowed to operate on all available cases, under the direction of the professors or assistants.

In order to give some idea of the way in which time is economised in comparison to the French schools, where one "hospital-lounge" occupies a whole morning, I subjoin a table of one day's work in the summer.

A.M. 7 to 8: Obstetrical Clinic. 8 to 9.30 : Surgical Clinic. 9.30 to 11: Medical Clinic. 11 to 12 : Surgical Policlinic

P.M. 12 to 1 : Ophthalmological Clinic. 1.45 to 3 : Medical Policlinic.

The rest of the day is filled up by theoretical lectures and practical courses in specialities, which the students attend or not at their own discretion and convenience.

If my description has succeeded in doing anything like justice to an admirable system of medical training, readers will not be disinclined to pardon the length at which I have accomplished this end.

Frankfort-on-the-Main.

\section{ON THE MODERN THEORY OF THE ACTION OF DIGITALIS. ${ }^{1}$}

BY EDWARD T. TIBBITS, M.D. LOND, PHYSICIAN TO THE BRADFORD INFIRMARY AND BRADFORD FEVER HOSPITAL.

NEARLY half a century ago the action of digitalis was thus described by Dr. Sigmond :- "It is upon the heart and the arterial system that digitalis acts; it diminishes the irritability of the constitution, and the frequency of the heart's action, \&c., and so produces diuresis." Much has been written about it since that time, but it is extremely doubtful whether at the present day any thing more is known with certainty concerning its action than is there set forth.

1 Read before the Leeds and West Riding Medico-Chirurgical Society, also before the Yorkshire Branch of the British Medical Association.
At the present time it is regarded as a cardiac tonic, and by some authorities it is even classed with ammonia, alcohol, \&c., and designated a cardiac stimulant. Moreover, it is said to increase arterial tension, and thus by virtue of this indefinite and very variable vascular condition to favour the flow of urine. In spite of numerous modern authors, its action as a depressant, or sedative (if the latter term be preferred), antiquated though it is, appears to me to be the only one which can be decidedly sustained.

In the first place, it may be observed that the experiments made upon animals have been misleading and unsatisfactory. In many instances the dose mentioned is poisonous, large, moderate. Such ill-defined doses must of necessity produce confusion. Traube showed that in dogs moderate doses of digitalis increased arterial pressure and diminished the frequency of the pulse. This statement is said to be confirmed by Boelim, Brunton, and Gourvat. An enormous rise of pressure is spoken of by some authors after the use of digitalis. An enormous rise of pressure is also said to be produced by strychnine. Do both these drugs act in the same direction? Some say digitalis arreste the heart's action in systole, others in diastole. Ackermann says that large doses increase arterial tension, and that it always acts by prolonging the diastole. Dr. Michael Foster tells us that a large dose of digitalis at first rapidly increases the general blood pressure, and the flow of urine is primarily arrested or diminished. The same author informs us, in another place, that the flow of urine is favoured by increase in general blood pressure, when there is increased frequency of the heart's action or constriction of the small arteries supplying other areas than the renal ones. Moreover, he says dis. tinctly that constriction of the renal artery diminishes the flow of urine. Hermann affirms that increased tension in the arterial system and in the renal artery itself produces a flow of urine or increased pressure in the glomeruli, owing to vaso-motor dilatation of the vasa efferentia.

But, again, notice the following remarks by Ackermann. The decrease of temperature after digitalin is caused by acceleration of the circulation in the peripheral portions of the body, and elsewhere he says it produces its effects by diminishing the size of the small arteries, and impeding the flow of blood through them. If the flow of blood be impeded through the small arteries, how is the peripheral circulation accelerated? Traube and Ackermann both say that digitalis in large doses lessens the tension of the aortic system in fevers to an important extent. Dr. M. Foster again says arterial tension is increased by digitalis when it produces diuresis. Dr. Lauder Brunton says exactly the reverse.

Granting, for the sake of argument, that arterial tension can be accurately estimated, but little reliance can be placed on it, since Müller finds that, in experiments on dogs, more than sixteen per cent. of the body weight of the anmal can be injected into the jugular vein without any marked increase of blood pressure. Within certain linits he says diminution of blood does not alter the blood pressure. This is directly opposed to Michael Foster and Hermann.

But further, supposing all experiments on animals to have been satisfactory, it does not follow that the same effect will happen in the human species. For it is well known that rabbits may eat belladouna and digitalis with impunity, and that the former does not affect the eye of the pigeon.

But, in the second place, the clinical evidence is equally unsatisfactory. Dr. Foster of Birmingham writes, "Digltalis in aortic disease (although there is said to be low arterial tension in this complaint) does harm, except when there is over-compensation, and throbbing and bounding of arteries all over the body, when it does good." How, I would ask? Is it by increasing arterial tension? The same physician also says, what others, including Fothergill, have endorsed, that diminution in the frequency of the heart's action under digitalis always means prolongation of the dia. stole. It is well to bear in mind that if this drug increases arterial tension, it prolongs the systole; hence it prolongs both systole and diastole, and we arrive by a periphrastic mode of expression at what no one can doubt-viz., that it diminishes the frequency of the heart's action. Fothergil further says that in aortic regurgitation, when there is intermission of the heart's action in the later stages, and a long diastole (notwithstanding the former statement that digitalis always means increase of diastole) it does away with the long diastolic halt, and excites more powerful ventricular contraction. Might I be permitted to ask whether these are demonstrations or simply hypotheses? 